Response to Commentaries on: The Effect of Integrating Music Listening With an Attachment-and Affective-Focused Short-Term Psychotherapy in an Individual With Relational Trauma: The Case of "James"

\title{
Facing the Music: Further Thoughts on Integrating Music into Psychotherapy G. PAUL BLIMLING ${ }^{\mathrm{a}, \mathrm{b}, \mathrm{c}}$
}

${ }^{a}$ Department of Psychiatry, Albany Medical College/Albany Medical Center, Albany, NY

${ }^{\mathrm{b}}$ Correspondence regarding this article should be sent to G. Paul Blimling, Albany Medical Center Department of Psychiatry, 25 Hackett Blvd, Albany, NY 12208

Email: blimlig@amc.edu

\begin{abstract}
In this article, I respond to the insightful commentaries by Karen Riggs Skean (2019), by Richard Harrison (2019), and by Ben Adams (2019) on my hybrid case study of "James," a survivor of chronic relational trauma (Blimling, 2019). These commentaries have stimulated me to think further about the impact of music on my individual psychotherapy work, both with James and with subsequent clients, and specifically with regard to its impact on my approach to group psychotherapy work. In addition, these commentaries have raised particular issues that I respond to, including, (a) constructive criticism by Skean and Harrison regarding the potential further use of "metaprocessing" and the developments made in Accelerated Experiential Dynamic Psychotherapy (AEDP) since I completed the Case of James; (b) Skean's perceptive point explaining how an individual therapist can take a personal passion-like music or literary writing or bicultural identity - and use it to enhance his or her enlivened presence in therapy with a client; and (c) Adams' thesis that music and psychotherapy both have their origins in the shamanistic practices of our hunter-gatherer ancestors, suggesting that the combination of psychotherapy and music is a kind of return to our very roots.
\end{abstract}

Key words: music listening; music and psychotherapy; music and emotions; experiential therapy; trauma treatment; AEDP; metaprocessing; therapist presence; psychotherapy integration; case study; clinical case study

\section{INTRODUCTION}

From the outset, the goal of the Case of James (Blimling, 2019) was to develop a theoretically sound hybrid model that utilized the ubiquity and visceral power of music in the service of reparative emotional experience. Diana Fosha's AEDP was selected due to its emphasis on such "bottom-up," here-and-now experiences of emotion in the context of a trusting therapeutic relationship as a fundamental means of change (Fosha, 2000). As outlined in the Case of James, the inclusion of music was pursued for its connection to memory (Janata, Tomik, Rankowski 2007); to social bonding (Malloch \& Trevarthen, 2010; Boer, Fischer, Strack, Bond, 
Lo, \& Lam, 2011); to self-identification (Boer et al 2011); to intrinsic emotional expression (Sacks, 2008); and also, in no small part, to my own identity as a musician.

I come from a musical family, and for as long as I can remember music has been a part of my daily life. From playing cello recitals to attending large, eclectic music festivals, music has been an integral part of my emotional and social development, and it is so much a part of my own identity that it has become nearly inextricable from my work as a psychologist. Since the publication of the original paper, I have been awed and impressed with the fundamental importance of music to my clients and their willingness to share such meaningful parts of themselves with me. This has been particularly meaningful in group work, as the utilization of music in this context has allowed for a cohesion and belongingness that has its root in shared experience. This sense of sharing of oneself, not just through words but through experience, is what makes the inclusion of music a unique and potent addition to such affect- and attachmentoriented treatment models as AEDP.

\section{AEDP AND THE "SECOND AVATAR"}

Perhaps one of the most informative and enlightening aspects of revisiting the Case of James in this context was receiving feedback from seasoned AEDP clinicians. Both Harrison and Skean reference AEDP's "second avatar," which represents an evolved second iteration of the AEDP model that emphasizes "metaprocessing" as a means of consolidating the experience of positive change. My original work was fundamentally based on Fosha's original model contained with her first seminal book, The Transforming Power of Affect (2000). The framework of an experientially-based model of affective change was ideally suited to the creation of a hybrid model that drew upon music as a potent addition to this kind of work.

Nevertheless, the second avatar shrewdly points out that a means of deepening and consolidating the shared experience is the use of "metaprocessing,"; that is, the drawing of attention to the process of the positive experience of change. This is undoubtedly a keen and effective way of highlighting the client's "transformance strivings" and aligning oneself with their "fundamental self-righting tendencies." I do think that such directly applied metainterventions may be particularly difficult with a patient as hostile and defended as James, who frequently reacted with hostility when interventions were too emotionally or experientially direct.

Harrison suggests, for example, that upon James' early attempts to fire me as his therapist, I could have inquired "how is it for you that I understand and respect your desire to get the best help available?" (Harrison, 2019, p. 180). I appreciate how this question keenly seeks to reach the transformance strivings of the client and represents an attempt to align with those "fundamental self-righting tendencies." However, I do wonder how this question would have landed with James, especially in this early stage of treatment. My sense is that this level of deep processing was not accessible to James in this moment, and any intervention that struck too close to the soft core of his underlying feelings would have been met with redoubled anger and defensive hostility. This is, in many respects, a primary reason for my inclusion of music in James' treatment, insofar as it represents an implicit means of sharing an emotional space that bypasses more superficial defenses that were so easily triggered. 
It should be noted that my approach to clinical practice is, in many inescapable ways, analogous to my approach to my study and performance of music. Just as in my career as a cellist, I have had many skillful and experienced teachers in my clinical training. Both have emphasized the importance of solid foundational skills and understandings that encompass best practice in the field, particularly with regard to which rules may be bent and which are best not. What I have taken from these encounters is the belief that a good student is not the one who seeks to imitate their teacher exactly, nor is the good teacher the one who insists on exact conformity to their own technique and musical interpretation. Rather, the relationship is such that the teacher provides a rationale and explanation for their methods while simultaneously adapting to the student's individual strengths and proclivities. Likewise, it is the student's responsibility to absorb and consider as much of the teacher's wisdom and experience as possible, while still retaining an individuality that allows the student to take what suits them well and to gracefully leave that which does not. These subtle differences in approach are what individuates both cellists and therapists alike, and which allow for a genuine expression that can be conveyed as both effective and unique.

\section{CREATIVITY AND CONNECTION}

As mentioned previously, my identity as a musician has greatly impacted the way in which I approach my therapeutic work. In any therapeutic context, we balance the application of our theory and the application of our person to the work, and music is a deeply authentic means of expression for me. As Skean (2019) wisely notes, there are multiple ways in which therapists may seek to apply their individual means of expression and connection to their work with individual patients, whether the medium is music (Blimling, 2015), creative writing (Pass, 2012), bicultural identity (Vigoda Gonzalez, 2018), or other forms of creative self-expression. While the literature supports the myriad benefits of including music specifically, there are many avenues for including our authentic selves in therapeutic relationships. However, the unique ubiquity and broad accessibility of music make it especially adaptable to psychotherapeutic work.

\section{CONTINUED USE OF MUSIC}

Since completing my graduate and postgraduate work in clinical psychology, I have continued to pursue my interest of incorporating music into aspects of my therapeutic practice. I now routinely ask new patients during their intake if they listen to music, and I have found that their answers can be illuminating. Patients will occasionally tell me that they have not listened to music in a long time, often out of the very fear of its evocative potential. I also find that the manner in which patients use music is informative; that is to say, does the individual use music as a means of social bonding and identification, or do they use it as a means of comforting escape from the social world? Who do the client cite as important influences on their choice of music, and is this a way that they retain a level of connection with that person? On a more superficial level, I have found that people are almost always eager to tell you about their favorite band, that song they have had stuck in their head for days, or the recent concert they attended. This brief question regarding an individual's preference in and use of music becomes a way of strengthening the alliance in and of itself. 
I have further found that the continued use of music with certain clients has been very effective and rewarding. I was just recently reminded by a client that I have seen for several years of the lasting effect that one such instance of collaborative music listening had on her, and she has kindly granted me permission to share it here. At the beginning of our work together, she had been so severely depressed that speaking in therapy seemed to be a monumental effort. She had presented on one particularly difficult week, her face blank and expressionless, and told me that talking about the depth of her feelings was more than she could bear. I gently suggested that perhaps we listen to a song of her choosing together, and she agreed. We sat together in my office and listened to a song by the Dave Matthews Band entitled "The Stone." The lyrics read, in part:

\author{
Oh, but this weighs on me \\ As heavy as stone and as blue as I go \\ I was just wondering if \\ You'd come along \\ Hold up my head when my head \\ Won't hold on \\ I'll do the same if the same's \\ What you want \\ But if not I'll go \\ I'll go alone.
}

The tune begins in a minor key and exhibits a consistent dissonance when the lyrics revolve around themes of despondence and isolation with a noticeable modulation to major chords when the lyrics shift to themes of connection and support. This seemed to reflect something important about her internal world, a sense of deep isolation and sadness, interspersed with a willingness to reach for connection, evidence of her own transformance strivings. At the time we originally listened together, I had admittedly not been impressed with any immediate effect; she left my office the same way she had arrived that day, and there were no overt indications that we had progressed in our work. It is only now, years later and with substantial improvement, that she told me how meaningful this was for her that I had taken an interest in her means of accessing her feelings, and that I had hung in with her even when she felt isolated and unable to communicate. We still occasionally talk about our shared love of music, especially the Dave Matthews Band, and she will occasionally gift me a song she feels I would appreciate.

\title{
"MUSIC AND MEANING" GROUP
}

Perhaps the most prominent way in which I have sought to pursue the use of music in a psychotherapeutic context has been with a group I began in November of 2017, called "Music and Meaning." This harkens back to my time working with recently returned veterans in graduate school and the ways I experienced how music can create a sense of cohesion and shared emotional experience that can be enormously facilitative in group work. The group, meeting for one hour once per week on Friday afternoons, is broadly inclusive and consists of adults with a range of diagnoses. There have been some changes in the structure and membership since its outset, but the fundamentals of the group have basically remained the same. Members write down the title and artist of music they would like to share and bring it to the meeting, where we 
take turns listening to the music together with the help of a pair of Bluetooth speakers and a music streaming service. Members are asked to listen open-mindedly and are reminded that the purpose is not necessarily to "like" everything that is shared, but rather to appreciate and understand it in the context of the individual who has chosen to share it. Members are further asked to provide disclaimers about their selection with regard to potentially triggering elements, such as explicit lyrics, startling noises, and so forth where appropriate before the song is played. Following the collective listening, the individual who selected the music will share its meaning for them, with other members free to inquire or to respond with their own thoughts and experiences.

It has been an extraordinary experience to see how sharing music in this way so easily facilitates cohesion and familiarity among group members, as well as the many purposes for which particular music has been chosen. Sometimes the music selection reflects a current situation in the group member's life, often with latent meaning that becomes more evident with discussion. Other times the choice of music represents a nostalgic childhood memory recently stirred, which not only serves to allow the individual to "show" other members a part of themselves, but also utilizes the song as a benchmark to identify a particular period in time that is relatable to other members. Sometimes one member's tune inspires another, and the spontaneous choice replaces the preplanned. This has been relatively common in the context of the group, in which members share a musical dialogue with one another where musical choices reflect a commentary on both implicit and explicit therapeutic material.

This dialogue speaks to the commentary by Adams (2019) regarding the question of spontaneous versus preplanned music and its relationship to interpersonal context and function. A particularly touching use of music occurs when one member offers a musical selection as a gift to another member, which often serves as an expression of understanding, empathy, and presence. Members have been known to jot down tunes that they discover from others in the group that they enjoy, and I keep a list of all the tunes that have been shared each meeting. I will occasionally compile these and share them with the members as a "group playlist." In the spirit of judicious self-disclosure, I will sometimes also participate in sharing a tune that is meaningful and important to me, and I find that members respond with warmth and curiosity.

\section{FUTURE DIRECTIONS}

Given the broad base of support and multiple established applications of music in clinical work, it is my hope that I will be able to extend my use of music in effective and meaningful ways. One particular aspiration is to start another music group for individuals suffering with dementia or Alzheimer's, both within the outpatient clinic in which I work and potentially on the medical floors of the hospital. There has been promising research supporting the use of music in "Reminiscence Therapy" with this population, including support for its efficacy in improving mood and some cognitive abilities (Cotelli, Manenti \& Zanetti, 2012). 


\section{THE LARGER CONTEXT}

Adams' (2019, p. 200) importantly discusses how

both music and psychotherapy have their historical origins in the ancient forms of psychological healing carried out by shamans in the societies of our hunter-gatherer ancestors (Eliade, 1951/1964; Frank \& Frank, 1993).

In such societies, some of which still exist today in various forms, there is no clear distinction between psychotherapist and musician. Rather, both of these roles are subsumed within the healing practices carried out by shamans. Shamans use music and dance as a way of entering into a trance state in which the shaman embarks on dreamlike metaphysical 'journeys' aimed at healing patient's physical and/or psychological illnesses (Harner, 1980; McClenon, 2001; Moreno, 1995; Wong, 1985).

Adams' point provides an exciting larger context for my clinical experience in combining psychotherapy and music. It is moving to know that my individual efforts touch a deep part of our common humanity, both across geography and back in time.

\section{CONCLUSION}

The Case of James represents an effort to compellingly illustrate the myriad and multifaceted ways in which music may augment a traditional psychotherapeutic approach. The thoughtful commentaries submitted by Skean, Harrison, and Adams affirm several ways in which facets of patient-chosen collaborative music listening are aligned with such therapeutic goals and techniques. Harrison (2019) points out how the use of "metaprocessing" may be beneficial in expanding and deepening the work. However, I have argued that such a technique would need to be skillfully and judiciously employed with a patient as hostile and defended as James, and that the shared experience of collaborative music listening may implicitly represent a kind of metaprocessing in itself.

The utility of music in "undoing aloneness" is also importantly explored through the commentaries, as well as the ways in which music represents an authentic form of selfexpression for myself and others.

In addition, I have discussed the ways in which I have continued to use music in my work, both in individual therapy and with groups, with an aspiration for the future development of a Reminiscence-Therapy-informed music group for individuals suffering from dementia and Alzheimer's.

Finally, as mentioned above, Adams' point about the connection between music and psychological healing reaching back in time to our lives as hunter-gathers provides an inspiring larger context to my work. 


\section{REFERENCES}

Adams, B.G. (2019) self-selected music for relational trauma: Commentary on the psychotherapy case of "James." Pragmatic Case Studies in Psychotherapy 15(2), Article 4, 198-205. Available: http://pcsp.libraries.rutgers.edu

Blimling, G.P. (2019). The effect of integrating music listening with an attachment- and affective-focused short-term psychotherapy in an individual with relational trauma: The case of "James." Pragmatic Case Studies in Psychotherapy 15(2), Article 1, 116-166. Available: http://pcsp.libraries.rutgers.edu

Boer, D., Fischer, R., Strack, M., Bond, M. H., Lo, E., Lam, J. (2011). How shared preferences in music create bonds between people: values as the missing link. Personality and Social Psychology Bulletin, 37(9), 1159-1171.

Cotelli, M., Maneti, R., Zanetti, O. (2012). Reminiscence therapy in dementia: A review. Maturitas, 72(3), 203-205.

Eliade, M. (1964). Shamanism: Archaic techniques of ecstasy (W. R. Trask, Trans.). Princeton, NJ: Princeton University Press. (Original work published 1951)

Fosha, D. (2000). The transforming power of affect: A model for accelerated change. New York: Basic Books.

Frank, J. D., \& Frank, J. B. (1993). Persuasion \& healing: A comparative study of psychotherapy ( $3^{\text {rd }}$ ed.). Baltimore, MD: Johns Hopkins University Press.

Harner, M. (1980). The way of the shaman. San Francisco: Harper.

Harrison, R. (2019). A bridge over troubled water: Commentary on Paul Blimling's case of "James" integrating music listening into AEDP. Pragmatic Case Studies in Psychotherapy 15(2), Article 3, 175-197. Available: http://pcsp.libraries.rutgers.edu

Janata, P., Tomic, S.T., \& Rakowski, S.K. (2007). Characterization of music-evoked autobiographical memories. Memory, 15(8), 845-860.

Malloch, S., \& Trevarthen, C. (2010). Musicality: Exploring the basis of human companionship. New York: Oxford university Press.

McClenon, J. (2001). Wondrous healing: Shamanism, human evolution, and origin of religion. DeKalb, IL: Northern Illinois University Press.

Moreno, J. J. (1995). Ethnomusic therapy: An interdisciplinary approach to music and healing. Arts in Psychotherapy, 22, 329-338.

Pass, E. R. (2012). Combining expressive writing with an affect- and attachment-focused psychotherapeutic approach in the treatment of a single-incident trauma survivor: The case of "Grace." Pragmatic Case Studies in Psychotherapy, 8(2), Article 1, 60-112. Available: http://pcsp.libraries.rutgers.edu.

Sacks, O. (2008). Musicophilia: Tales of music and the brain. Toronto, CA: Alfred A. Knopf Inc.

Skean, K. (2019). Integrating client-chosen music in relational trauma treatment: Pathways to the heart. Pragmatic Case Studies in Psychotherapy 15(2), Article 2, 167-174. Available: http://pcsp.libraries.rutgers.edu

Trevarthen, C. \& Malloch, S. (2002). The musical lives of babies and families. Journal of Zero to Three, 23(1), 35-40. 
Pragmatic Case Studies in Psychotherapy, http://pcsp.libraries.rutgers.edu

Volume 15, Module 2, Article 5, pp. 206-213, 07-10-19 [copyright by author]

Vigoda Gonzalez, N. (2018). The merits of integrating accelerated experiential dynamic psychotherapy and cultural competence strategies in the treatment of relational trauma: The case of "Rosa. Pragmatic Case Studies in Psychotherapy, 14(1), Article 1, 1-57. Available: http://pcsp.libraries.rutgers.edu.

Wong, L. T. (1985). Shamanic art in healing rituals. Saybrook Review, 5, 55-63. 